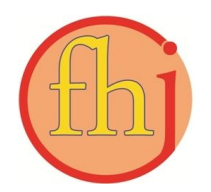

Faletehan Health Journal, 5 (1) (2018) 10-18

https://journal.Ippm-stikesfa.ac.id

ISSN 2088-673X | e-ISSN 2597-8667

\title{
Implementasi Hot Work Permit System sebagai Upaya Pencegahan Kecelakaan Kerja
}

\author{
Fitri Ayu Lestari ${ }^{1}$, Andiko Nugraha Kusuma ${ }^{1 *}$, Wiwik Eko Pertiwi ${ }^{1}$ \\ ${ }^{1}$ Program Studi Kesehatan M asyarakat STIKes Faletehan Serang, Indonesia \\ * Corresponding Author: andiko.kusuma@yahoo.com
}

\begin{abstract}
Abstrak
Hot Work Permit System adalah sistem ijin tertulis untuk melakukan pekerjaan yang menghasilkan sumber panas. Penelitian ini bertujuan untuk mengetahui hubungan antara pengetahuan, masa kerja, dan sikap pekerja dengan implementasi hot work permit system pada Departemen M echanichal White Paper di PT. Indah Kiat Pulp and Paper Tbk Serang Tahun 2017. Penelitian bersifat cross sectional. Populasi penelitian ini adalah seluruh karyawan pada Departemen Mechanichal White Paper yang berjumlah 50 orang. Sampel penelitian ini adalah seluruh total populasi. Pengumpulan data primer menggunakan kuesioner dengan teknik wawancara. Hasil univariat menunjukan bahwa $58,0 \%$ pekerja memiliki implementasi tinggi, $66,0 \%$ pekerja memiliki pengetahuan tinggi, sebanyak $74,0 \%$ memiliki masa kerja $\geq 10$ tahun, dan $64,0 \%$ pekerja memiliki sikap positif. Hasil uji statistik menunjukan ada hubungan antara pengetahuan pekerja ( $\mathrm{Pv}: 0,008)$ dan sikap $(\mathrm{Pv}: 0,000)$ dengan implementasi hot work permit system. Saran kepada perusahaan untuk meningkatkan pelaksanaan budaya safety mengenai penerapan hot work permit system, melaksanakan program training untuk pekerja pengelasan, dan melaksanakan sistem sosialisasi pada pekerja mengenai standar operasional prosedur (SOP) sikap kerja.
\end{abstract}

Kata kunci: Hot work, Permit system, Pengelasan

\begin{abstract}
The Hot Work Permit System is a written permission system for doing work that generates a heat source. The aims of this research is to determine the correlation between knowledge, working period, and attitude of workers with the implementation of hot work permit system at the Department of Mechanichal White Paper at PT. Indah Kiat Pulp and Paper Tbk Serang year 2017. The research is cross sectional. The population of this study is all employees at the Department of Mechanichal White Paper which amounted to 50 people. The sample of this study is the total population. Primary data collection using questionnaires with interview techniques. Univariate results showed that $58.0 \%$ of workers had high implementation, $66.0 \%$ had high knowledge, $74.0 \%$ had a working life of $\geq 10$ years, and $64.0 \%$ had a positive attitude. The result of statistical test shows that there is relation between worker knowledge (Pv: 0,008 ) and attitude (Pv: 0,000) with hot work permit system implementation. Suggestion to the company to improve the implementation of safety culture about the implementation of hot work permit system, implement training program for welder, and implement socialization system to the workers regarding standard operational procedure (SOP) worker attitude.
\end{abstract}

Keyword: Hot work, Permit system, Welding 
Faletehan Health Journal, 5 (1) (2018) 10-18 https://journal.Ippm-stikesfa.ac.id ISSN 2088-673X | 2597-8667

\section{Pendahuluan}

Penggunaan mesin, alat kerja, material dan proses produksi pada sektor industri telah menjadi sumber bahaya yang dapat menyebabkan terjadinya kecelakaan kerja termasuk bahaya kebakaran. Kebakaran berpontensi menimbulkan kerugian baik bagi manusia, harta benda maupun lingkungan. Apabila terjadi kebakaran terutama pada sektor industri akan banyak pihak yang merasakan dampaknya, antara lain pihak perusahaan, pekerja, pemerintah, maupun kepentingan pembangunan nasional (Kepmenaker RI No. 186 tahun 1999).

Menurut data Intenational Labour Organization (ILO), pada tahun 2012 kasus kebakaran pada sektor industri dunia mengakibatkan 426 orang meninggal (ILO, 2012). Sementara berdasarkan jumlah kasus kebakaran yang berasal dari aktivitas pekerjaan panas dari tahun 2009 sampai tahun 2014 terjadi sebanyak 16 kasus, diantaranya pada tahun 2012, kasus Kecelakaan Kerja (KK) yang berkaitan dengan hot work terjadi di sebuah SPBU yang meledak akibat sisa residu gas pengurasan tangki terkena percikan api yang timbul dari pengelasan tanpa dilengkapi dengan perizinan yang lengkap. Pada tahun 2013 PT. Nagamas Palmoil Lestari (NPL) di kawasan Pelindo Dumai, Provinsi Riau, terbakar akibat percikan api las mengenai busa yang berfungsi sebagai isolasi dan peredam mesin produksi serta tangki (Raya, 2014 ).

Menurut data dari Badan Penanggulangan Becana Daerah (BPBD) Kabupaten Serang, diketahui pada tahun 2016 telah terjadi 5 kejadian kebakaran pada sektor industri, diantaranya kebakaran yang terjadi di PT. Golden Key Bojonegara akibat dari kesalahan pekerja yang tidak mengikuti standar operasi prosedur kerja panas pada saat proses pengelasan sehingga percikan api mengenai bahan yang mudah terbakar (BPBD, 2016).

Hot work dapat didefinisikan sebagai pekerjaan yang berkaitan dengan pembakaran, pengelasan, atau kegiatan serupa yang dapat menimbulkan percikan api atau ledakan (Raya, 2014). National Fire Protection Assosiation (NFPA) 51 B tahun 2009 menyebutkan bahwa potensi bahaya utama pada aktivitas hot work adalah kebakaran dan ledakan. Salah satu jenis pekerjaan panas (hot work) adalah pekerjaan yang berhubungan dengan kelistrikan dan pengelasan.
Mengingat potensi kebakaran yang tinggi pada pekerjaan panas, maka diperlukan upaya pencegahan melalui sistem manajemen kebakaran (Permana, 2015). Sistem manajemen kebakaran adalah suatu upaya terpadu untuk mengelola risiko kebakaran melalui perencanaan, pelaksanaan, pemantauan dan tindak lanjutnya (Ramli, 2010). Kegiatan terpadu dalam mengelola resiko kebakaran diantaranya adalah dengan menerapkan sistem ijin kerja (work permit), yang digunakan untuk mengendalikan resiko kebakaran adalah sistem ijin kerja panas (hot work permit) (Tarwaka, 2012). Beberapa penelitian menyebutkan bahwa penerapan hot work permit yang tepat dapat memimalisasi terjadinya potensi kebakaran. Raya (2014), menyebutkan bahwa penerapan hot work permit system (sistem ijin kerja panas) di PT. Acidatama di area 200 dan cooling tower telah mencapai tingkat kesesuaian $90,5 \%$. Sedangkan menurut penelitian Wiedyanto (2014) di PT. Pertamina, diketahui terdapat hubungan yang kuat antara pengetahuan pekerja tentang prosedur, penerapan ijin kerja panas, dan perilaku aman kerja yaitu sebesar 97,22 \%. Perilaku aman dalam bekerja dapat mencegah terjadinya kecelakaan dan kebakaran.

PT. Indah Kiat Pulp and Paper Tbk Serang merupakan salah satu industri yang beroperasi di bidang manufaktur produksi kertas, bubur kertas, dan kemasan dengan material mudah terbakar. Selain itu, PT. Indah Kiat Pulp and Paper Tbk juga merupakan perusahaan multinasional yang memiliki tingkat aktivitas produksi yang tinggi serta aktivitas pekerjaan panas yang tinggi pula. Aktivitas pekerjaan panas yang tinggi tersebut adalah pengelasan dan perbaikan mesin yang berpotensi menimbulkan kebakaran. Berdasarkan data sekunder PT. Indah Kiat Pulp and Paper Tbk Serang, diketahui pada tahun 2014 terjadi kebakaran akibat percikan api las yang mengenai bubur kertas kering. Pada tahun 2015, terjadi kebakaran akibat pekerja tidak mengikuti prosedur pencegahan kebakaran yang terdapat di form izin kerja panas (hot work permit). Pada tahun 2016, terjadi kebakaran akibat pengelasan yang dilakukan pekerja tidak sesuai dengan layout/ lokasi yang tertera pada form surat izin kerja panas (hot work permit) yang disebabkan oleh ketidaktahuan pekerja. Tujuan dari penelitian ini adalah untuk mengetahui implementasi Hot Work Permit System pada 
Departemen Mechanical White Paper di PT. Indah Kiat Pulp and Paper Tbk Serang tahun 2017.

\section{Metode Penelitian}

Penelitian ini menggunakan pendekatan cross sectional, dengan cara pendekatan observasi atau pengumpulan data sekaligus pada saat yang sama (Notoatmodjo, 2010).

Penelitian ini dilakukan di Departemen Mechanical White Paper PT. Indah Kiat Pulp and Paper Tbk Desa Kragilan Kecamatan Kragilan Kabupaten Serang Provinsi Banten pada bulan Mei hingga Juli tahun 2017. Populasi dalam penelitian ini adalah pekerja pada Departemen Mechanical White Paper di PT. Indah Kiat Pulp and Paper Tbk Serang sebanyak 50 pekerja dan sampel penelitian ini adalah seluruh jumlah populasi. Data yang diperlukan dalam penelitian ini berupa data primer yang diperoleh dengan cara wawancara menggunakan alat ukur kuesioner yang berisi 15 pertanyaan dan telah dilakukan uji validitas dan reliabilitas dengan hasil semua pertanyaan dalam kuesioner ini dinyatakan valid dan reliabel. Analisis data penelitian ini menggunakan analisis univariat dan bivariat dengan uji chi square test. Uji signifikan dilakukan dengan menggunakan batas kemaknaan $\alpha($ alpha $)=5 \%$ dan confidance interval $95 \%$ (Hastono, 2016).

\section{Hasil dan Pembahasan \\ Implementasi Hot Work Permit System}

Berdasarkan tabel 1, diketahui bahwa dari 50 pekerja yang melaksanakan pekerjaan panas terdapat $21(42,0 \%)$ pekerja yang menunjukkan implementasi hot work permit rendah dan terdapat $29(58,0 \%)$ pekerja yang menunjukkan implementasi hot work permit tinggi.

Hot work permit system adalah sistem ijin kerja tertulis dari atasan pekerja yang bersangkutan untuk melakukan pekerjaan yang menghasilkan sumber panas. Pekerjaan yang dapat menghasilkan sumber panas disebut pekerjaan panas (Tarwaka, 2012). Hot work permit system diterapkan sebagai bentuk program pengendalian potensi kebakaran pada perusahaan yang memiliki material dan proses yang mudah terbakar yang mengacu pada ketetapan Occuptional Health and Safety Assesment (OHSAS) 18001 tahun 2007 dan Peraturan Pemerintah No 50 tahun 2012 mengenai Sistem
Manajemen Keselamatan dan Kesehatan Kerja terutama mengidentifikasi operasi-operasi dan kegiatan perubahan, modifikasi serta perbaikan peralatan yang dapat menimbulkan bahaya.

Berdasarkan hasil penelitian diketahui bahwa dari 50 pekerja yang melaksanakan pekerjaan panas terdapat $21(42,0 \%)$ pekerja memiliki implementasi hot work permit rendah dan terdapat $29(58,0 \%)$ pekerja yang memiliki implementasi hot work permit tinggi. Implementasi dengan frekuensi terbanyak yaitu mengenai pekerja tidak boleh meninggalkan lokasi pengelasan sebelum dilakukan pengecekan ulang oleh petugas safety sebanyak 29 responden $(58,0 \%)$, peralatan pemadam kebakaran harus diletakan di lokasi pekerjaan pengelasan berlangsung sebanyak 17 responden $(34,0 \%)$, dan pekerjaan panas tidak boleh dilaksanakan diluar layout yang tertera dalam form hot work permit sebanyak 3 responden $(6,0 \%)$.

Hasil tersebut menggambarkan bahwa sebagian responden sudah melaksanakan implementasi hot work permit system yang diterapkan di perusahaan dalam kegiatan pekerjaan pengelasan oleh mekanik sehari-hari. Sedangkan masih ada sebagian kecil responden yang belum melaksanakan hot work permit system dalam kegiatan pekerjaan sehari-hari. Hal ini menggambarkan bahwa belum terbentuknya komitmen secara keseluruhan pada pekerja mekanik dalam mengiplementasikan program pengendalian kebakaran hot work permit system.

Menurut Boediono (2008), komitmen, kepedulian, dan kepatuhan pekerja terhadap pelaksanaan K3 merupakan kunci dari suatu keberhasilan program keselamatan dan kesehatan kerja di perusahaan. Implementasi responden dalam suatu program keselamatan dapat dipengaruhi oleh beberapa faktor yaitu faktor internal yang berasal dari dalam diri responden dan faktor eksternal yang berasal dari lingkungan manajemen perusahaan.

Tabel 1. Implementasi Hot Work Permit System

\begin{tabular}{lcc}
\hline $\begin{array}{c}\text { Implementasi hot } \\
\text { work permit }\end{array}$ & Frekuensi & $\%$ \\
\hline Rendah & 21 & 42,0 \\
\hline Tinggi & 29 & 58,0 \\
\hline Jumlah & 50 & 100,0 \\
\hline
\end{tabular}

Latar belakang pendidikan, motivasi, dan cara pandang responden merupakan contoh faktor internal yang mempengaruhi implementasi 
Faletehan Health Journal, 5 (1) (2018) 10-18 https://journal.Ippm-stikesfa.ac.id ISSN 2088-673X | 2597-8667

program hot work permit system para responden. Selain itu, penerapan sistem target produksi yang meningkat dari perusahaan menyebabkan setiap seksi/ bagian berlomba-lomba menyelesaikan pekerjaan secara tepat waktu akibatnya departemen yang bertanggung jawab pada proses perbaikan, dan modifikasi mesin peralatan produksi termotivasi bekerja secara cepat sehingga kadang melupakan aspek keselamatan dan kesehatan kerja seperti bekerja sesuai standar operasional prosedur.

Hal lain yang menjadi faktor eksternal terhadap implementasi hot work permit adalah tidak selalu tersedianya sarana dan prasana keselamatan dan kesehatan kerja yang disediakan perusahaan. Kadang kala karyawan melakukan pekerjaan panas berupa pengelasan tanpa menggunakan sarung tangan dan apron las akibat tidak tersedianya peralatan. Selain itu pada saat observasi di lokasi penelitian, ditemukan responden yang menempelkan formulir hot work permit di sembarang tempat karena kurangnya jumlah papan pekerjaan panas yang di sediakan perusahaan. Hal semacam ini sering terjadi di area pekerjaan Departemen White Paper di PT Indah Kiat Pulp and Paper Serang.

\section{Pengetahuan, Masa Kerja dan Sikap}

Karakteristik responden dalam penelitian ini terdiri dari pengetahuan, masa kerja dan sikap. Penelitian menunjukkan hasil, pada tabel 2, diketahui bahwa dari 50 pekerja terdapat sebanyak 17 (34\%) yang mempunyai pengetahuan rendah dan $33(66 \%)$ mempunyai pengetahuan yang tinggi. Sebanyak $13(26,0 \%)$ pekerja memiliki masa kerja baru dan terdapat 37 (74,0\%) pekerja yang memiliki masa kerja lama. Sebanyak $18(36,0 \%)$ pekerja memiliki sikap negatif dan dan $32(64,0 \%)$ pekerja yang memiliki sikap positif.

\section{Hubungan antara Pengetahuan dengan Implementasi Hot Work Permit System}

Hasil penelitian yang menunjukkan hubungan antara pengetahuan dengan implementasi hot work permit tergambar dari tabel 3.

Berdasarkan tabel 3 diketahui bahwa dari 17 pekerja yang melakukan pekerjaan panas yang memiliki pengetahuan rendah terdapat $12(70,6 \%)$ pekerja yang melaksanakan implementasi hot work permit rendah dan terdapat 5 (29,4\%) pekerja yang melaksanakan implementasi hot work permit tinggi. Sedangkan dari 33 Pekerja yang melakukan pekerjaan panas yang memiliki pengetahuan tinggi terdapat $9(27,3 \%)$ pekerja yang melaksanakan implementasi hot work permit rendah dan terdapat $24(72,7 \%)$ pekerja yang melaksanakan implementasi hot work permit tinggi.

Tabel 2. Distribusi Frekuensi Faktor-faktor yang Mempengaruhi Hot Work Permit System

\begin{tabular}{lcc}
\hline Variabel & Jumlah & $\begin{array}{c}\text { Persentase } \\
(\boldsymbol{\%})\end{array}$ \\
\hline Pengetahuan & & \\
$-\quad$ Rendah & 17 & 34 \\
$-\quad$ Tinggi & 33 & 66 \\
\hline Masa Kerja & & \\
$-\quad$ Baru & 13 & 26 \\
$-\quad$ Lama & 37 & 74 \\
\hline Sikap & & \\
$-\quad$ Negatif & 18 & 36 \\
$-\quad$ Positif & 32 & 64 \\
\hline Total & $\mathbf{5 0}$ & $\mathbf{1 0 0}$ \\
\hline
\end{tabular}

Tabel 3. Hubungan antara Pengetahuan dengan Implementasi Hot Work Permit System

\begin{tabular}{|c|c|c|c|c|c|}
\hline \multirow{2}{*}{ Pengetahuan } & \multicolumn{2}{|c|}{ Implementasi Hot Work Permit } & \multirow{2}{*}{ Jumlah } & \multirow{2}{*}{$\mathrm{P}$ value } & \multirow[b]{2}{*}{$\begin{array}{c}\text { OR } \\
(95 \% \mathrm{CI})\end{array}$} \\
\hline & Rendah & Tinggi & & & \\
\hline Rendah & $12(70,6 \%)$ & $5 \quad(29,4 \%)$ & $17(100 \%)$ & 0,008 & 6,400 \\
\hline Tinggi & $9 \quad(27,3 \%)$ & $24(72,7 \%)$ & $33(100 \%)$ & & \\
\hline Jumlah & $21(42,0 \%)$ & $29(58,0 \%)$ & $50(100 \%)$ & & \\
\hline
\end{tabular}




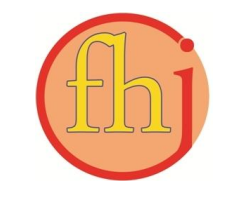

Hasil uji statistik dengan menggunakan uji chi square diperoleh nilai $\mathrm{p}=0,008$ maka dapat disimpulkan secara statistik pada $\alpha \quad 5 \%$ ada hubungan yang signifikan antara pengetahuan pekerja yang melakukan pekerjaan panas dengan implementasi hot work permit system pada Departemen White Paper di PT. Indah Kiat Pulp and Paper Tbk Serang. Dengan nilai OR=6,400 artinya pekerja yang melakukan pekerjaan panas yang memiliki pengetahuan rendah mempunyai peluang 6,4 kali tidak melaksanakan implementasi hot work permit system dibandingkan dengan pekerja yang pengetahuan tinggi. Hasil penelitian ini sejalan dengan hasil penelitian (Kurniawan, 2006) yang menunjukan bahwa secara statistik ada hubungan antara tingkat pengetahuan responden dengan penerapan Prosedur Keselamatan Kerja di PT. Buna Kimia Ungaran.

Pengetahuan merupakan hasil dari tahu, dan ini terjadi setelah orang melakukan pengindraan terhadap suatu objek tertentu. Pengindraan terjadi melalui pancaindra manusia, yakni indra pengelihatan, pendengaran, penciuman, rasa dan raba (Notoatmodjo, 2007). Hasil penelitian menunjukkan bahwa pengetahuan dengan frekuensi tertinggi yaitu mengenai memasang rambu-rambu pada saat pekerjaan pengelasan dilaksanakan sebanyak 23 responden $(46,0 \%)$, melakukan upaya pencegahan terhadap material mudah terbakar sebanyak 10 responden $(20,0 \%)$, dan memeriksa kodisi peralatan dan lokasi pekerjaan pengelasan sebanyak 7 responden $(14,0 \%)$.

Hasil penelitian juga menggambarkan bahwa sebagian besar dari responden sudah memiliki pengetahuan tinggi terkait program hot work permit system di perusahaan. Hal ini menunjukkan sudah tersedianya informasi dan edukasi responden mengenai K3. Sesuai dengan pernyataan Skinner (1938) dalam Notoatmodjo (2005) bahwa seseorang memiliki pengetahuan tinggi apabila mampu mengungkapkan sebagian besar informasi dari suatu objek dengan benar. Sedangkan proporsi sebagian kecil responden menggambarkan belum menyeluruhnya informasi dan edukasi mengenai K3 di perusahaan. Hal ini disebabkan dari perbedaan kemampuan indra dan pemahaman yang dimiliki responden serta kefektifan dari program informasi dan edukasi K3 yang diterapkan. Seperti dalam penelitian ini dapat dilihat dari pengisian kuesioner masih terdapat pekerja yang memiliki pengetahuan rendah mengenai hot work permit system.

Hasil penelitian menunjukan bahwa 17 Pekerja yang melakukan pekerjaan panas berupa pengelasan yang mempunyai pengetahuan rendah sebanyak $12(70,6 \%)$ pekerja yang memiliki implementasi rendah. Pengetahuan yang rendah mengenai hot work permit system dapat dipengaruhi dari latar belakang pelatihan dan pemberian informasi mengenai. Menurut pekerja yang diwawancarai di Departemen Mechanichal White Paper, sosialisasi mengenai program K3 hanya diperoleh ketika awal masuk kerja dengan pokok bahasan secara umum dan pada kegiatan safety mindset tiap minggu sehingga tidak ada pelatihan khusus terkait hot work permit system di perusahaan. Akibatnya masih ada pekerja yang memiliki pengetahuan rendah mengenai hot work permit system.

Seperti diketahui bahwa tingkat pengetahuan pekerja yang tinggi akan memberikan respon yang baik terhadap implementasi program keselamatan khusus implementasi hot work permit system di perusahaan. Pengetahuan adalah hasil pengindraan manusia terhadap objek melalui indra yang dimilikinya seperti mata, hidung, dan alat indra lainnya. Dengan sendirinya pada waktu pengindraan sampai menghasilkan pengetahuan tersebut sangat dipengaruhi oleh intensitas perhatian dan persepsi terhadap objek. Pengetahuan ini merupakan faktor yang sangat penting untuk terbentuknya tindakan seseorang (Notoatmodjo, 2007).

Oleh karena itu pengetahuan pekerja sangat berpengaruh terhadap peran pekerja dalam melaksanakan pekerjaan panas berupa pengelasan sesuai dengan hot work permit system yang telah ditetapkan diperusahaan. Upaya yang dapat dilakukan dengan memberikan edukasi melalui training khusus bagi pelaksana pekerja pengelasan secara berkelanjutan. Tujuan dari training ini untuk merefresh pengetahuan pekerja sehingga bekerja sesuai dengan SOP dan menumbuhkan pemahaman mengenai pentingnya K3 dalam pencegahan kecelakaan khususnya kebakaran.

\section{Hubungan antara Masa Kerja dengan Implementasi Hot Work Permit System}

Hasil penelitian yang menunjukkan hubungan antara masa kerja dengan implementasi hot work permit tergambar dari tabel 4 , bahwa 
Faletehan Health Journal, 5 (1) (2018) 10-18 https://journal.Ippm-stikesfa.ac.id ISSN 2088-673X | 2597-8667

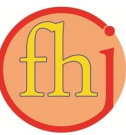

dari 13 pekerja yang melakukan pekerjaan panas yang memiliki masa kerja baru terdapat $2(15,4 \%)$ pekerja yang melaksanakan implementasi hot work permit rendah dan terdapat $11(84,6 \%)$ pekerja yang melaksanakan implementasi hot work permit tinggi. Sedangkan dari 37 pekerja yang melakukan pekerjaan panas yang memiliki masa kerja lama terdapat $19(51,4 \%)$ pekerja yang melaksanakan implementasi hot work permit rendah dan terdapat $18(48,6 \%)$ pekerja yang melaksanakan implementasi hot work permit tinggi. Hasil uji statistik dengan menggunakan uji chi square diperoleh nilai $\mathrm{p}=0,053$ maka dapat disimpulkan secara statistik pada $\alpha 5 \%$ tidak ada hubungan yang signifikan antara masa kerja pekerja yang melakukan pekerjaan panas dengan implementasi hot work permit system pada Departemen Mechanichal White Paper di PT. Indah Kiat Pulp and Paper Tbk Serang. Hasil penelitian ini tidak sejalan dengan hasil penelitian (Almani, 2013) berdasarkan hasil uji chi square menunjukan bahwa nilai $p=0,008$ atau $<0,05$ artinya terdapat hubungan yang signifikan antara masa kerja dengan penerapan sistem keselamatan dan kesehatan kerja.

Masa kerja dengan frekuensi terbanyak yaitu pada masa kerja 20 tahun sebanyak 7 orang $(14,0 \%)$, masa kerja 22 tahun sebanyak 6 orang $(12,0 \%)$, dan masa kerja 26 tahun sebanyak 6 orang $(12,0 \%)$. Hasil ini menggambarkan sebagaian besar pekerja di Departemen Mechanichal White Paper merupakan pekerja yang telah bekerja lebih dari 10 tahun yang masuk dalam kategori pekerja lama. Sedangkan sebagian kecil lain menggambarkan bahwa masih ada pekerja yang memiliki masa kerja baru yaitu kurang dari 10 tahun. Masa kerja atau pengalaman kerja merupakan faktor yang dapat mempengaruhi terjadinya kecelakaan akibat kerja. Pengalaman bekerja sangat ditentukan oleh lamanya seseorang bekerja. semakin lama dia bekerja maka semakin banyak pengalaman dalam bekerja (Sucipto, 2014).
Berdasarkan hasil penelitian menunjukkan bahwa masa kerja atau pengalaman kerja tidak mempengaruhi implementasi hot work permit system. Masa kerja yang lama tidak menjamin bahwa pekerja memiliki implementasi hot work permit system tinggi dan masa kerja baru tidak menjamin pula bahwa memiliki implementasi hot work permit rendah. Hal ini dapat disebabkan oleh faktor internal dari pekerja. Faktor internal diantaranya dari umur pekerja, umur yang lebih muda cenderung memiliki rasa ingin tahu yang tinggi terhadap program dan hal-hal baru terkait pekerjaannya. Akibat dari seringnya mencari tahu maka tidak menutup kemungkinan pekerja dengan masa kerja baru yang memiliki umur lebih muda memiliki pengetahuan hot work permit system yang tinggi oleh karena itu menyebabkan implementasi hot work permit system juga tinggi. Sedangkan pada pekerja dengan masa kerja lama, memiliki umur yang lebih tua cenderung memiliki rasa ingin tahu yang rendah dan telah mengalami fase jenuh untuk menggali informasi baru terkait pekerjaannya oleh karena itu menyebabkan implementasi hot work permit system pada masa kerja lama masih ada yang rendah.

Faktor internal lainnya adalah latar belakang pendidikan. Pekerja dengan masa kerja baru ratarata memiliki latar belakang pendidikan sedang atau telah lulus perguruan tinggi sedangkan seluruh pekerja dengan masa kerja lama memiliki latar belakang pendidikan SMA oleh karena latar belakang pendidikan yang berbeda menyebabkan pemahaman yang berbeda pula. Jenjang pendidikan yang lebih tinggi diasumsikan memiliki pemahaman lebih baik, sehingga tidak menutup kemungkinan pekerja dengan masa kerja baru sudah memiliki implementasi hot work permit system yang tinggi.

Hal lain yang menyebabkan tidak ada hubungan antara masa kerja dengan implementasi hot work permit system adalah dari perbandingan frekuensi jumlah pekerja masa kerja baru yang jauh lebih sedikit dengan jumlah pekerja masa kerja lama.

Tabel 4. Hubungan antara Masa Kerja dengan Implementasi Hot Work Permit System

\begin{tabular}{|c|c|c|c|c|}
\hline \multirow{2}{*}{ Masa kerja } & \multicolumn{2}{|c|}{ Implementasi Hot Work Permit } & \multirow{2}{*}{ Jumlah } & \multirow{2}{*}{$\mathrm{P}$ value } \\
\hline & Rendah & Tinggi & & \\
\hline Baru & $2(15,4 \%)$ & $11(84,6 \%)$ & $13(100 \%)$ & 0,053 \\
\hline Lama & $19(51,4 \%)$ & $18(48,6 \%)$ & $37(100 \%)$ & \\
\hline Jumlah & $21(42,0 \%)$ & $29(58,0 \%)$ & $50(100 \%)$ & \\
\hline
\end{tabular}




\section{Hubungan antara Sikap dengan Implementasi Hot Work Permit System}

Hasil penelitian yang menunjukkan hubungan antara sikap dengan implementasi hot work permit tergambar dari tabel 5. Berdasarkan tabel 5, diketahui bahwa dari 18 pekerja yang melakukan pekerjaan panas yang memiliki sikap negatif terdapat $17(94,4 \%)$ pekerja yang melaksanakan implementasi hot work permit system rendah dan terdapat $1(5,6 \%)$ pekerja yang melaksanakani implementasi hot work permit system tinggi. Sedangkan dari 32 pekerja yang melakukan pekerjaan panas yang memiliki sikap positif terdapat $21(42,0 \%)$ pekerja yang melaksanakan implementasi hot work permit system rendah dan terdapat $29(58,0 \%)$ pekerja yang melaksanakan implementasi hot work permit system tinggi. Hasil uji statistik dengan menggunakan uji chi square diperoleh nilai $\mathrm{p}=0,000$ maka dapat disimpulkan secara statistik pada $\alpha 5 \%$ ada hubungan yang signifikan antara sikap pekerja yang melakukan pekerjaan panas berupa pengelasan dengan implementasi hot work permit system pada Departemen White Paper di PT. Indah Kiat Pulp and Paper Tbk Serang. Hasil analisis diperoleh nilai $\mathrm{OR}=11,90$ artinya pekerja yang melakukan pekerjaan panas yang memiliki sikap negatif mempunyai peluang 11,9 kali tidak melaksanakan implementasi hot work permit system dibandingkan dengan pekerja yang memiliki sikap positif. Hasil penelitian ini sejalan dengan hasil penelitian (Siahaan, 2005) yang menyebutkan bahwa terdapat hubungan yang signifikan antara sikap K3 dengan komitmen terhadap penerapan program K3.

Sikap merupakan produk dari proses sosialisasi dimana seseorang bereaksi sesuai dengan rangsangan yang diterimanya (Notoatmodjo, 2007). Sikap merupakan respon positif dan negative terhadap suatu objek atau situasi (Widiyatun, 1999). Berdasarkan hasil penelitian diketahui bahwa dari 50 pekerja yang melaksanakan pekerjaan panas terdapat 18 $(36,0 \%)$ pekerja memiliki sikap negatif dan terdapat $32(64,0 \%)$ pekerja yang memiliki sikap positif. Sikap positif dengan frekuensi tertinggi yaitu sebanyak 32 responden $(64,0 \%)$ sangat setuju bertanggung jawab atas proses pekerjaan pengelasan agar berjalan aman dan menganalisa potensi kebakaran di lokasi, sebanyak 25 responden $(50,0 \%)$ sangat menyetujui adanya penerapan program hot work permit system di perusahaan, dan sebanyak 25 responden $(50,0 \%)$ sangat menyetujui bahwa pekerjaan pengelasan tidak akan melaksanakan pekerjaan pengelasan tanpa alat pemadam di lokasi pekerjaan. Sikap positif tersebut antara lain disebabkan karena sudah tersedianya kegiatan K3 secara terkoordinasi dan teratur. Baiknya koordinasi pihak safety dengan responden serta komunikasi antara setiap responden dalam departemen tentang sumber bahaya dan manfaat K3 dilingkungan kerja menumbuhkan sikap peduli keselamatan satu sama lain.

Sikap negatif terhadap implementasi hot work permit system yang ditunjukkan oleh responden yaitu menyetujui meletakan form hot work permit di tempat yang aman bukan menempel dilokasi pekerjaan $(48,0 \%)$, sebanyak 23 responden $(46,0 \%)$ sangat menyetujui menjauhkan material mudah terbakar sesuai kebutuhan bukan sesuai SOP yang ditetapkan yaitu 5 meter, dan sebanyak 18 responden $(36,0 \%)$ menyetujui meletakan peralatan pekerjaan panas di lokasi pekerjaan setelah bekerja yang seharusnya diletakan di ruang peralatan. Sikap negatif responden berasal dari belum menyeluruhnya informasi dari pihak safety perusahaan kepada pekerja pengelasan mengenai cara yang tepat dan aman untuk tempat meletakan form hot work permit, jarak meletakan material mudah terbakar, dan tempat melatakan peralatan pengelasan setelah dilakukan pekerjaan.

Tabel 5. Hubungan antara Sikap dengan Implementasi Hot Work Permit System

\begin{tabular}{|c|c|c|c|c|c|}
\hline \multirow{2}{*}{ Sikap } & \multicolumn{2}{|c|}{ Implementasi Hot Work Permit } & \multirow{2}{*}{ Jumlah } & \multirow{2}{*}{$\mathrm{P}$ value } & \multirow[b]{2}{*}{ OR $(95 \% \mathrm{CI})$} \\
\hline & Rendah & Tinggi & & & \\
\hline Negatif & $17(94,4 \%)$ & $1 \quad(5,60 \%)$ & $18(100 \%)$ & 0,000 & 119,000 \\
\hline Positif & $4(12,5 \%)$ & $28(87,5 \%)$ & $32(100 \%)$ & & \\
\hline Jumlah & $21(66,0 \%)$ & $29(34,0 \%)$ & $50(100 \%)$ & & \\
\hline
\end{tabular}


Faletehan Health Journal, 5 (1) (2018) 10-18 https://journal.Ippm-stikesfa.ac.id ISSN 2088-673X | 2597-8667

Sikap negatif ini juga dapat berasal dari faktor internal diri responden yang belum memahami bahwa kebiasaan-kebiasaan yang tidak sesuai dengan standar operasional prosedur (SOP) ini jika terus dilaksanakan berulang-ulang cepat atau lambat akan menimbulkan bahaya bagi pekerja maupun kerugian bagi perusahaan. Pemberian edukasi melalui training serta kegiatan safety talk perlu dilaksanakan secara lebih menyeluruh khususnya mengenai hot work permit system agar pekerja lebih memahami dan dapat menumbuhkan komitmen dalam diri pekerja sehingga pihak manajemen mengetahui sejauh mana pemahaman pekerja khususnya pelaksana pengelasan dalam bersikap yang aman dan selamat. Hal ini dapat menjadi salah satu langakah pencegahan sebelum terjadinya tindakan terbuka dari pekerja yang dapat membahayakan keselamatan diri serta kerugian perusahaan.

Menurut Widiyatun (1999), menjelaskan sikap adalah kecenderuangan manusia untuk berespon secara positif atau negatif terhadap suatu objek atau situasi. Sikap merupakan produk dari proses sosialisasi dimana seseorang bereaksi sesuai dengan rangsangan yang diterimanya (Notoatmodjo, 2007). Kecenderungan pekerja bersikap negatif atau positif diperoleh berdasarkan informasi dan komunikasi K3 yang diperoleh pekerja sesuai dengan pengalaman bekerja sehingga ada perbedaan penanggapan sikap pada diri masing-masing pekerja.

Penjelasan diatas sesuai dengan pendapat Mar'at (1982) dalam buku Notoatmodjo (2007) yang mengatakan bahwa sikap merupakan produk dari proses sosialisasi dimana seseorang beraksi sesuai dengan rangsangan yang diterimanya. Rangsangan yang diterima oleh pekerja dapat berasal dari sistem manajemen yang diterapkan di perusahaan. Sebagian pekerja yang di wawancara pada saat penelitian menjelaskan bahwa mereka kadang merasa malas mengikuti SOP karena dirasa rumit dan menghambat penncapaian target pekerjaan. Ketersediaan peralatan pelindung diri yang memadai juga dapat menjadi rangsangan bagi pekerja. Menurut sebagian pekerja bahwa peralatan yang digunakan sekarang sebagian sudah tidak layak pakai dan mengganggu kenyaman seperti sepatu safety yang sudah rusak. Rangsangan lainnya dapat berasal dari dalam diri pekerja yang tidak mendukung berjalannya program karena latar belakang dan alasan pribadi seperti memilih bekerja dengan cara dan kebiasaan sediri. Oleh sebab itu maka perlu adanya edukasi berkelanjutan mengenai hot work permit system baik mengenai tujuan dan manfaat dari program tersebut yang akan merangsang pekerja untuk bersikap positif. Upaya yang dapat dilakukan dengan pemberian training khusus mengenai hot work permit system untuk pelaksana pekerjaan panas sehingga mereka memahami bahwa seluruh program keselamatan kerja khususnya hot work permit system tetap harus dijalankan sesuai standar yang berlaku agar selamat dan target produksi tetap tercapai. Upaya lain yang dapat dilaksanakan dalam merangsang sikap adalah memberikan reward and punishment pada pekerja sehingga pekerja yang menjalankan pekerjaan sesuai standar khususnya pengelasan akan merasa hasil kerjanya dihargai oleh perusahaan dan pekerja yang bersikap negatif akan terangsang untuk mengikuti standar yang benar dalam bekerja.

\section{Simpulan}

Berdasarkan hasil penelitian diketahui bahwa $58,0 \%$ pekerja memiliki implementasi hot work permit system kategori tinggi dan terdapat hubungan antara pengetahuan pekerja $(\mathrm{Pv}: 0,008)$ dan sikap (Pv: 0,000) dengan implementasi hot work permit system. Tidak ada hubungan antara masa kerja (Pv: 0,053) dengan implementasi hot work permit system.

\section{Daftar Referensi}

Badan Penanggulangan Bencana Daerah Kabupaten Serang. (2016)

Budiono, S. (2008). Bunga Rampai HIPERKES dan KK. Semareng : Universitas Diponegoro

Dewi, RP. (2012). Analisis Implementasi Teknis Pencegahan dan Penanggulangan Kebakaran pada Pabrik la dan $1 b$ di Industri Pupuk X (Berdasarkan Standar Indonesi). Volume 1, No. 2, Halaman 783805. diakses 21 Maret 2017 (http://ejournals1. undip.ac.id/jkm)

Dahlawy, AD. (2008). Faktor-faktor yang Mempengaruhi Perilaku Keselamatan dan kesehatan Kerja (K3) di Area Pengolahan PT. ANTAM Tbk Kabupaten Bogor. Jakarta: Universitas Islam Negeri Syarif 
Hidayatullah Program Studi Kesehatan Masyarakat.

Evarts, B. (2010). Home and Non-home Fires Involving Torches, Burners, and Soldering Equipment, NFPA Fire Analysis and Research, Quency : Burningtown Massachusetts, diakses 10 Maret 2017. (http://www.nfpa.org/research/reports-andstatistcs/fire-causes/appliances-andequipment/home-and-non-home-firesinvovling-torches-and-burners)

Hastono, P S. (2016). Analisis Data pada Bidang Kesehatan. Jakarta : PT. Raja Grafindo Persada

International Labour Organization (ILO). 2012. Fire Risk Management, ILO Geneva, diakses tanggal 8 Mei 2017, (http://www.ilo.org/wcmsp5/wcms_194781.pdf)

Keputusan Menteri RI No 186. (1999). Penanggulangan Kebakaran di Tempat Kerja. Jakarta : Pemerintah Republik Indonesia

Khaqim, ES. (2014). Analisis Sistem Ijin Kerja terhadap Kejadian Kecelakaan Kerja di PT. Bakrie Contruction. Surakarta : Fakultas kesehatan Masyarakat Universitas Muhammadiyah Surakarta

Kurniawan, B., Lestantyo, D., \& Murtiningsih, D., (2006). Jurnal Promosi Kesehatan Indonesia : Hubungan Karakteristik Pekerja dengan Praktik Penerapan Prosedur Keselamatan Kerja di PT. Bina Buna Kimia Ungaran. Vol 1, No. 2, Hal 2825 diakses $21 \quad$ Maret 2017 (http://ejournals1. undip.ac.id/jkm)

National Fire Protection Assosiation. (2009). Standar for Fire Preventing During Welding, Cutting, and Other Hot Work, An
International Codes and Standard Organization, Quincy.

Notoatmodjo, S. (2005). Metodologi Penelitian Kesehatan. Jakarta : Rineka Cipta

Notoatmodjo, S. (2007). Promosi Kesehatan dan Ilmu Perilaku. Jakarta : Rineka Cipta

Notoatmodjo, S. (2010). Promosi Kesehatan Teori dan Aplikasi Edisi Revisi. Jakarta : Rineka Cipta

Occuptional Health and Safety Asessment Series 18001, (2007). Sistem Manajemen Keselamatan dan Kesehatan KerjaPersyaratan.

Peraturan Pemerintah No 50. (2012). Sistem Manajemen Keselamatan dan Kesehatan Kerja. disahkan di Jakarta

Permana, Yoga. (2015). Evaluasi Penerapan Ijin Kerja Panas Sebagai Upaya Pencegahan di PT. Indonesia Power UPB Semarang. Semarang : Universitas Negeri Semarang

Ramli, S. (2010). Manajemen Keselamatan dan Kesehatan Kerja. Jakarta: Dian Rakyat

Raya, dkk . (2014). Analisis Penerapan Surat Izin Kerja Panas pada Bagian Plantis Di PT. Indo Acidatama, Tbk (Berdasarkan Guidance on Permit to Work System Tahun 2005). Volume 2, No. 3, Halaman 214-222, diakses 20 Mei 2017, (http://ejournals1.undip.ac.id/jkm)

Sucipto, CD. (2014). Keselamatan dan Kesehatan Kerja. Yogyakarta : Gosyen Publishing

Tarwaka. (2012). Keselamatan dan Kesehatan Kerja : Dasar-dasar Keselamatan Kerja serta Pencegahan Kecelakaan di Tempat Kerja. Surakarta : Harapan Press

Widayatun, RT. (1999). Ilmu Perilaku M.A. 104 "Buku Pegangan Mahasiswa AKPER". Jakarta : CV. Sagung Seto 